\title{
Response to: Analysis of Functional and Radiological Outcome Following Lumbar Decompression without Fusion in Patients with Degenerative Lumbar Scoliosis
}

\author{
Akshay Dharamchand Gadiya ${ }^{1}$, Mandar Deepak Borde ${ }^{1}$, Nishant Kumar ${ }^{1}$, \\ Priyank Mangaldas Patel ${ }^{2}$, Premik Bhupendra Nagad ${ }^{1}$, Shekhar Yeshwant Bhojraj ${ }^{1}$ \\ ${ }^{1}$ Department of Orthopaedics, The Spine Clinic, Lilavati Hospital and Research Center, Mumbai, India \\ ${ }^{2}$ Department of Orthopaedics, Jupiter Hospital, Thane, India
}

Dear Editor,

We appreciate the letter regarding our manuscript entitled "Analysis of the functional and radiological outcomes of lumbar decompression without fusion in patients with degenerative lumbar scoliosis [1].” We are very grateful to the reader for the appreciation of the article. We also feel the concerns raised by the reader are legit.

This was a retrospective analysis of 51 consecutive patients undergoing lumbar decompression for lumbar canal stenosis (LCS) associated with degenerative lumbar scoliosis (DLS). Patients having DLS of more than $10^{\circ}$ along with LCS, radiculopathy, and significant claudication undergoing stand-alone lumbar decompression were included in the cohort. This has been described in the methodology. The authors agree that the good outcome with lumbar decompression in the present study was due to mild scoliosis in the cohort. Importantly this study underlines the important fact that good outcomes are persistent in the long term.

In the author's practice, patients having symptomatic LCS with DLS after failed conservative treatment are fur- ther considered for lumbar decompression. Patients with DLS are offered deformity correction along with instrumentation only when the back pain is either due to facet arthropathy or fatigue arising because of coronal and sagittal imbalance. All the patient's in this study underwent conventional open lumbar laminectomy along with medial facetectomy. The extent of decompression was decided upon preoperative magnetic resonance imaging as well as the extent of distribution of radicular pain. Whenever a possible attempt was made to preserve the integrity of the facet joint without compromising on neural decompression by performing undercutting of medial facets.

We strongly believe radiological instability is never a true representative of clinical instability of the lumbar spine. This notion is echoed in literature quite often [24]. Moreover, patients undergoing lumbar decompression without fusion for LCS sometimes also report on improvement in clinically significant back pain $[5,6]$. As per the Kirkaldy-Willis hypothesis, a degenerated spine will eventually progress from phase of instability to a phase of auto-stabilization thus making the spinal deformity of less functional consequence. Rustenburg et al. [7] questioned

Received Jun 15, 2020; Accepted Jun 19, 2020

Corresponding author: Akshay Dharamchand Gadiya

Department of Orthopaedics, The Spine Clinic, Lilavati Hospital and Research Center, Bandra Reclamation, Bandra West, Mumbai 400050, India

Tel: +91-9930282040, Fax: +91-22226405119, E-mail: akshaygadia@gmail.com 
the need for instrumentation to avoid instability in patients with DLS.

It is quite important to highlight again that this study does not establish the supremacy of decompression over fusion for a given patient of DLS but reports on the good outcomes of lumbar decompression especially when the symptoms of patient are predominantly related to neural compression and when the spinal deformity is not the main driving force for the symptoms of patients. Plethora of literature exist on the improvement in the quality of life after deformity correction in patients with DLS [8], but health-related quality of life scores underestimate the impact of major complications associated with these surgeries [9]. Hence, one needs to be very careful while selecting an appropriate patient for a particular type of surgery.

We again thank readers to raise these valid and legit questions. The authors would be more than happy to answer further queries if any.

\section{Conflict of Interest}

No potential conflict of interest relevant to this article was reported.

\section{References}

1. Gadiya AD, Borde MD, Kumar N, Patel PM, Nagad PB, Bhojraj SY. Analysis of the functional and radiological outcomes of lumbar decompression without fusion in patients with degenerative lumbar scoliosis. Asian Spine J 2020;14:9-16.

2. Goel A. Beyond radiological imaging: direct observation and manual physical evaluation of spinal instability. J Craniovertebr Junction Spine 2017;8:88-90.
3. Fox MW, Onofrio BM, Onofrio BM, Hanssen AD. Clinical outcomes and radiological instability following decompressive lumbar laminectomy for degenerative spinal stenosis: a comparison of patients undergoing concomitant arthrodesis versus decompression alone. J Neurosurg 1996;85:793-802.

4. Harmon PH. Indications for spinal fusion in lumbar diskopathy, instability and arthrosis: I. anatomic and functional pathology and review of literature. Clin Orthop Relat Res 1964;34:73-91.

5. Crawford CH 3rd, Glassman SD, Mummaneni PV, Knightly JJ, Asher AL. Back pain improvement after decompression without fusion or stabilization in patients with lumbar spinal stenosis and clinically significant preoperative back pain. J Neurosurg Spine 2016;25:596-601.

6. Jones AD, Wafai AM, Easterbrook AL. Improvement in low back pain following spinal decompression: observational study of 119 patients. Eur Spine J 2014;23:135-41.

7. Rustenburg CM, Faraj SS, Holewijn RM, et al. The biomechanical effect of single-level laminectomy and posterior instrumentation on spinal stability in degenerative lumbar scoliosis: a human cadaveric study. Neurosurg Focus 2019;46:E15.

8. Wang G, Hu J, Liu X, Cao Y. Surgical treatments for degenerative lumbar scoliosis: a meta analysis. Eur Spine J 2015;24:1792-9.

9. Glassman SD, Bridwell KH, Shaffrey CI, et al. Healthrelated quality of life scores underestimate the impact of major complications in lumbar degenerative scoliosis surgery. Spine Deform 2018;6:67-71. 